\title{
THE ION ENERGY IN A PLASMA RESONATOR EXCITED BY A POWERFUL MICROWAVE PULSE AT ECR FREQUENCY
}

\author{
A.N. Antonov, V.S. Antipov, E.A. Kornilov, V.A. Miroshnichenko, V.A. Vinokurov \\ National Science Center "Kharkov Institute of Physics and Technology", Kharkiv, Ukraine
}

The possibility of heating argon plasma ions with a density of $\approx 10^{13} \mathrm{~cm}^{-3}$ to $2 \mathrm{keV}$ in a resonator placed in a magnetic field of a plug configuration when oscillations were excited at an electron-cyclotron resonance frequency with an electric field strength of up to $12 \mathrm{kV} / \mathrm{cm}$ in a pulse with a duration of $1.8 \mu$ s was shown experimentally. Ions acquire high energy in the fields of stochastic low-frequency ion oscillations due to the development of a modified decay of microwave oscillations.

PACS: 52.35.Mw

It has been shown experimentally that the possibility of heating argon plasma ions with a density of $\approx 10^{13} \mathrm{~cm}^{-3}$ to $2 \mathrm{keV}$ in a resonator placed in a magnetic field of a plug configuration when oscillations are excited at an electron-cyclotron resonance frequency at an electric field strength of up to $12 \mathrm{kV} / \mathrm{cm}$ in a pulse with a duration of $1.8 \mu$ s. Ions acquire high energy in the fields of stochastic low-frequency ion oscillations due to the development of a modified decay of microwave oscillations.It was previously established that when a certain value of the electric field is exceeded, the excited oscillations at the frequency of electron-cyclotron resonance undergo modified decay [1 - 7]. As a result of the development of this nonlinear process, new microwave oscillations with a lower frequency and low-frequency ion oscillations are born. The growth increment of lowfrequency oscillations reaches hundreds of periods of a decaying wave-oscillation. The oscillations are irregular in nature, accompanied by chaotic phase changes.

It was shown [1 - 3,6] that in the fields of such microwave oscillations, plasma electrons acquire energy of hundreds of $\mathrm{keV}$. In this case, HF oscillations excited from outside should transmit a significant part of their energy to LF oscillations. In turn, in the fields of these oscillations, plasma ions must also experience effective acceleration and heating. The objective of this work was to verify this assumption.

The experimental studies, as in $[5,6]$, were carried out in a cavity filled with plasma upon excitation in it of microwave electromagnetic oscillations by an electric field of the order of $12 \mathrm{kV} / \mathrm{cm}$ at the frequency of electron-cyclotron resonance (ECR).

The experimental setup is shown in Fig. 1. The cylindrical resonator is placed coaxially with the axis of the magnetic trap. The resonator is made of a copper pipe having an internal diameter of 16 and a length of $60 \mathrm{~cm}$, which was powered by oscillations from a $320 \mathrm{~kW}$ magnetron generator in a pulse of $1.8 \mu$ s duration on $\mathrm{H}_{10 \mathrm{x}}$ and $\mathrm{H}_{20 \mathrm{x}}$ modes at a frequency of $2.77 \mathrm{GHz}$. The end walls of the resonator contain movable pistons, the movement of which achieves maximum energy transfer from the magnetron to the resonator in the selected mode. Oscillations are brought into the central part of the cavity along the length of a rectangular waveguide with a section of $72 \times 34 \mathrm{~mm}$ with its narrow wall located along the cavity axis. Oscillations were introduced into the resonator in the region of the minimum magnetic field of $0.1 \mathrm{~T}$. The cork ratio of the trap was 1.2 .
The preliminary plasma in the resonator with a density of $10^{8} \ldots 10^{10} \mathrm{~cm}^{-3}$ was created by an electron beam with a current of $60 \ldots 100 \mathrm{~mA}$, a diameter of $2 \mathrm{~cm}$, and an energy of $600 \mathrm{eV}$, due to a beam-plasma discharge (point 2 of Fig. 1). The beam was injected along the cavity axis at an argon gas pressure in the trap of $4 \cdot 10^{-4}$ Torr. To measure the density, temperature, and plasma potential, a Langmuir probe was used [9]. The probe was located in the central part of the resonator and could move along the radius. When microwave power was introduced into the plasma above $50 \mathrm{~kW}$, the plasma density increased to $10^{13} \mathrm{~cm}^{-3}$.

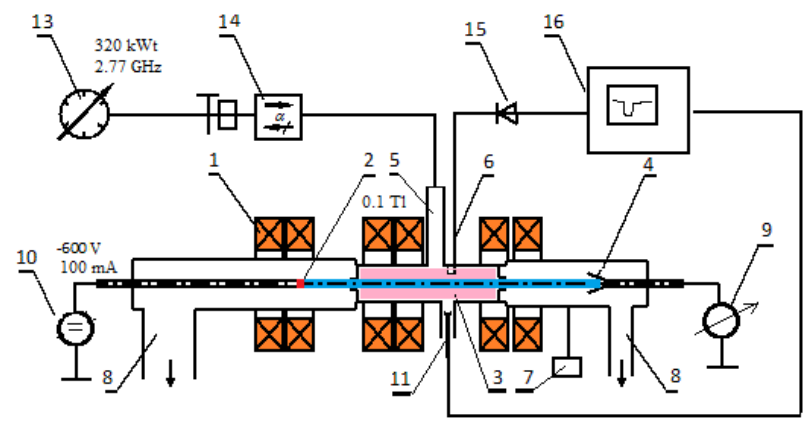

Fig. 1. The experimental setup:

1 - solenoid coils of a constant magnetic field;

2 - an electron gun forming an electron beam;

3 - a microwave cavity chamber; 4 - receiving collector

of particles; 5 -microwave input into the resonator

(waveguide $72 \times 34 \mathrm{~mm}$ ); 6 - receiving loop probe;

$7-$ a system for introducing gas into the sealed chamber of the installation; 8 -pumps of the system pumping system; 9 - ammeter collector electric current meter; 10 - power supply of the electron gun; 11 -ion sensor;

13 - magnetron; 14 -microwave valve; 15 -detector head of the loop probe; 16 - an oscilloscope

To measure the ion energy, we used the method proposed in [11] and developed in [8]. The method is based on taking into account the motion of charged particles in a narrow channel across the magnetic field. In contrast to [8], in which the authors used the indicated method for measure the electron energy distribution function, in this paper the method is used to estimate the energy of positively charged argon ions.

In this case, a sensor is used in the form of a copper tube with an internal diameter of 0.8 and a length of $8 \mathrm{~cm}$. A current collector with a diameter of $0.7 \mathrm{~cm}$ isolated from the housing is located inside the tube and moves along its length. The sensor is located in the central part of the magnetic trap and its axis is perpendicu- 
lar to the lines of force of the magnetic field (in a homogeneous region of the magnetic field of the trap). The open side of the copper tube is on the side of the chamber. Through it, ions fall on the current collector of the sensor. The opposite side of the tube is hermetically sealed with a bushing. The gas pressure in the sensor and the cavity chamber is the same. The measurement of ion energy is based on the separation of particles by charge and energy in a magnetic field at the location of the sensor. The electronic component is separated from the ions by a transverse magnetic field. The sensor allows you to evaluate the energy of argon ions in the range from a dozen $\mathrm{eV}$ to several $\mathrm{keV}$ in the conditions existing in the installation.

The arrangement of the sensor, the elements of the registration scheme of the potential value of the collector of the sensor at its location $(h)$, and the probe for recording oscillations in the resonator are shown in Fig. 2.

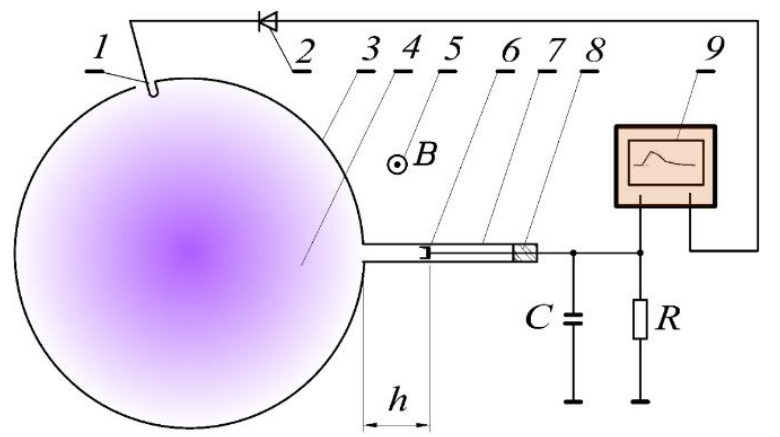

Fig. 2. The scheme for measuring the energy of ions:

1 -loop probe for registering a microwave signal in the resonator; 2 -detector head; 3 - cavity chamber with a diameter of 16 and length $60 \mathrm{~cm} ; 4$-plasmas; 5 -direction of the induction vector of a constant magnetic field; 6 -current collector of the ion probe;

7 - a tube with an inner diameter of $0.8 \mathrm{~cm} ; 8$ - insulator; 9 -an oscilloscope; $h$ is the distance between the inner boundary of the chamber and the current collector; $C=402 \mathrm{pF}$-capacitance of the measuring chain; $R=1 M \Omega-$ oscilloscope input impedance

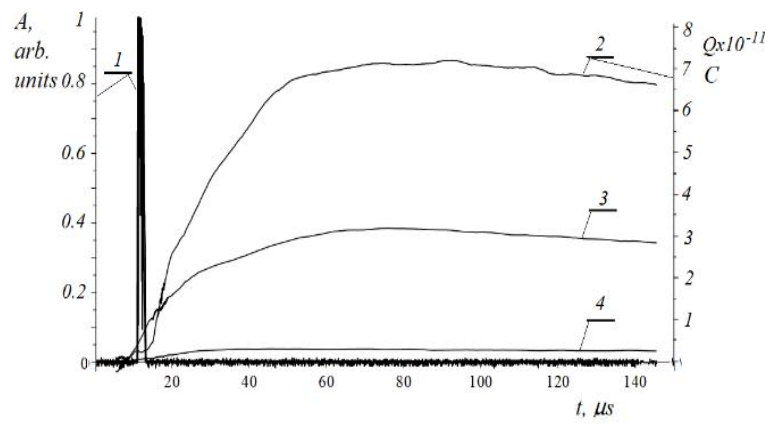

Fig. 3. The relationship between the charge current collector of the sensor (2) and the microwave pulse (1) in the plasma resonator. The sensor collector is located at a distance of $2-h=0.45 \mathrm{~cm} ; 3-h=1 \mathrm{~cm}$;

$$
4-h=1.6 \mathrm{~cm}
$$

In Fig. 3 shows the oscillogram of the microwave signal recorded in the plasma at an input power of $320 \mathrm{~kW}$ and a graph of the collector charge located in the ion sensor at distances $\mathrm{h}(0.45 ; 1 ; 1.6 \mathrm{~cm})$ depending on the measurement time. The charge was calculated by the measured potential of the collector relative to the camera body loaded with a measuring chain containing a capacitance of $402 \mathrm{pF}$ and a resistance of $1 \mathrm{M} \Omega$. The presented results were obtained under conditions of the presence of low-frequency oscillations in the plasma having a random character with a spectrum extending to $300 \mathrm{MHz}$.

It is estimated that the travel time of argon ions with an energy of $1000 \mathrm{eV}$ from the far side of the chamber to the sensor collector is approximately $2.5 \mu \mathrm{s}$, and with an energy of $10 \mathrm{eV}, 8.7 \mu \mathrm{s}$. It can be seen that the charging time of the sensor with ions that can get into the sensor from the indicated areas after the microwave pulse has expired (see indicated by a number 1 Fig. 3) is less than the charge accumulation time on the collector and reaches a value of the order of $80 \mu$ s (see curves 2, 3, 4 of Fig. 3). After this time, charge leakage through the input resistance of the oscilloscope prevails. A long charge accumulation time may be due to the ionization of the gas by high-energy electrons held by a magnetic trap.

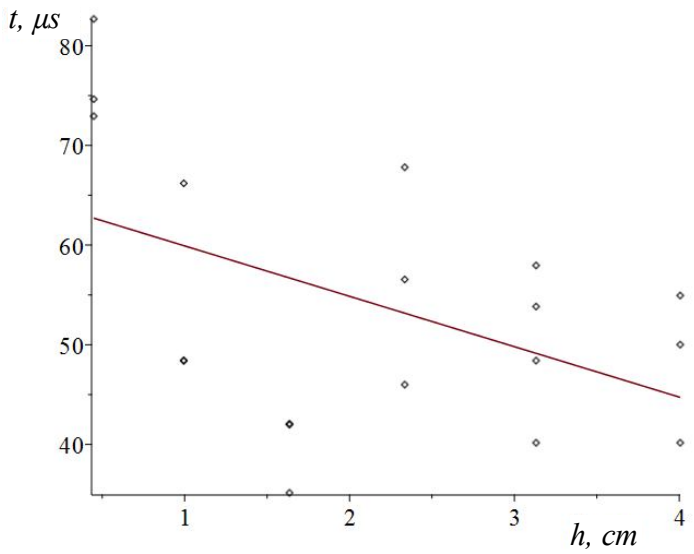

Fig. 4. Charging time of the collector of the ion sensor located at a distance $h$ (Fig. 2)

In Fig. 4 dots indicate the measured times of the maximum value of the potential of the collector of the ion sensor at various distances of the collector position $\mathrm{h}$ and the straight line interpolating them, carried out by minimizing its standard deviation from the measured data. The charge completion time of the ion sensor collector was determined from waveform graphs similar to those shown in Fig. 3 at the time of their maximum value. At this point in time, the total charging current of the capacitance C (see Fig. 2) turns to 0 . The displayed dependence of Fig. 4 indicates that the number of ions with higher energy decreases in the system faster than the number of ions with lower energy.

The energy of argon ions was estimated in full accordance with the method presented in [8] as follows.

If we assume that a non-monoenergetic argon ion flux consists of seven mono-energetic fluxes with energies from 10 to $2000 \mathrm{eV}$, then the total charge on the sensor collector from these fluxes will be as shown in Fig. 5 by number 8 . The graphs of the dependence of the magnitude of the charge on the collector as a function of the depth of its immersion $h$, normalized with respect to the maximum measured charge, were obtained by numerically simulating the motion of singly charged argon ions in a constant magnetic field of the setup $(0.1 \mathrm{~T})$. In this case, the ratios of the charges of individual beams are selected in such a way that their total charge (indicated by number 8 Fig. 5) gives the 
smallest mean-square deviation with respect to the measured charge values [11]. This procedure was performed by repeatedly sorting random values of the curve values (see indicated by numbers $1-7$ Fig. 5) in the range from zero to the maximum value of the measured charge.

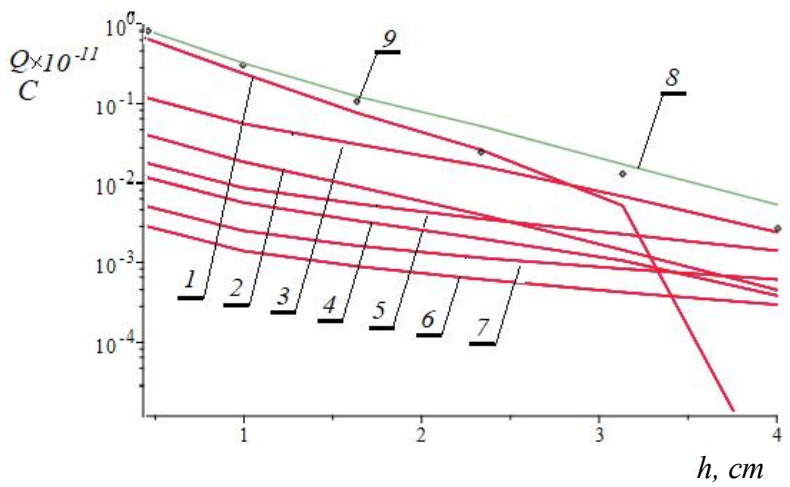

Fig. 5. Calculated charge of an argon ion beam

by the received collector, depending on its position

in the sensor: $1-10 \mathrm{eV} ; 2-50 \mathrm{eV} ; 3-100 \mathrm{eV}$;

$4-200 \mathrm{eV} ; 5-500 \mathrm{eV} ; 6-1000 \mathrm{eV} ; 7-2000 \mathrm{eV}$;

8 -total calculated charge of all beams (1-7);

9 - measured values of the probe collector charge

The resulting functions determine the energy of each beam and allow you to build a graph of the dependence of the number of ions on their energy for some values of their energy. The larger the number of positions of the sensor collector and the smaller the error in measuring the sensor potential, the more accurately the dependence of the distribution of argon ions falling on the sensor collector on their energy is displayed. Using the dependences of the charge magnitude of each beam with its own energy (i.e., the areas bounded by the curve Qi (h), where $i=1 \ldots 7$, see Fig. 5), the total charge of all the beams is calculated. Under the assumption that predominantly singly charged argon ions are deposited on the collector, their energy distribution can be represented by the graph shown in Fig. 6, where $\mathrm{N}$ is the number of ions deposited on the collector of the sensor.

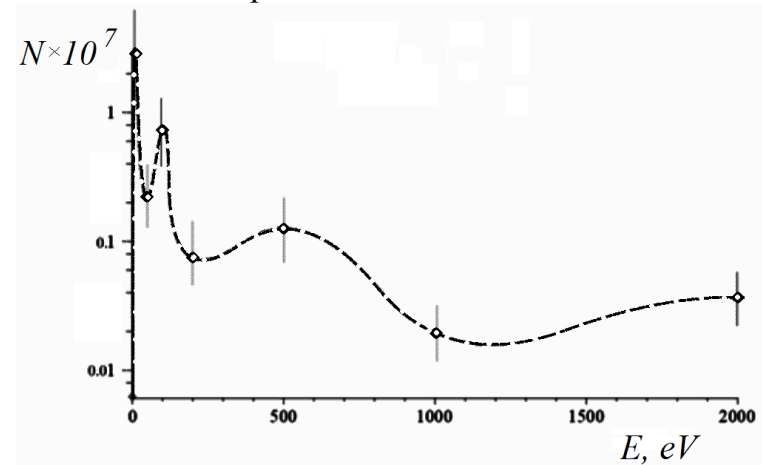

Fig. 6. The distribution of argon ions by energy

The presented graph indicates that there are argon ions with energies up to $2 \mathrm{keV}$ in the plasma.

The obtained experimental results make it possible to conclude that with the development of modified decay of waves of high field strength excited at the electron-cyclotron resonance frequency, energy can be transferred to dense plasma ions.

The authors are deeply grateful to V.A. Buts, I.K. Kovalchuk, A.P. Tolstoluzhsky for a discussion of the results of the work and valuable comments, G.V. Sotnikova for the assistance in the performance of work.

This work was partially supported by the budget program of Ukraine "Support to the most important areas of scientific research" (KPKVK 6541230).

\section{REFERENCES}

1. V.A. Buts, O.V. Manujlenko, K.N. Stepanov, A.P. Tolstoluzhsky. Chaotic dynamics of charged parti-cles at wave-particle type interaction and chaotic dy-namics at weak nonlinear interaction of wave-wave type // Plasma Physics. 1995, v. 20, № 9, p. 794-801.

2. A.N. Antonov, V.A. Buts, O.F. Kovpik, E.A. Kornilov, O.V. Manuilenko, V.G. Svichensky, K.N. Stepanov, Yu.A. Turkin. Stochastic plasma heating during electron cyclotron resonance // JETP Letters. 1999, v. 69, Issue 11, p. 806-811.

3. A.N. Antonov, V.A. Buts, I.K. Kovalchuk, O.F. Kovpik, E.A. Kornilov, V.G. Svichensky, D.V. Tarasov. Regular and Stochastic decays of Waves in a Plasma Cavity // Plasma Physics Reports. 2012, v. 38, № 8, p. 636-650.

4. A.N. Antonov, V.A. Buts, O.F. Kovpik, E.A. Kornilov, I.K. Kovalchuk, V.G. Svichensky, D.V. Tarasov. Using modified decay to form stochastic oscillation spectra in a plasma // Problems of Atomic Science and Technology. Series "Nuclear Physics Investigations”. 2008, № 5, p. 100-104.

5. A.N. Antonov, V.A. Buts, E.A. Kornilov, V.V. Kuzmin, V.G. Svichensky. Investigations of energetic distribution of plasma electrons in conditions of overlapping of cyclotron resonances // Fizicheskie osnovy priborostroeniya. Inzhenernaya fizika. 2015, № 1, p. 56-66 (in Russian).

6. A.N. Antonov, V.S. Antipov, E.A. Kornilov, V.A. Vinokurov. Features of Behavior of Electrons of Plasma in Open Trap in Condition of Transverse Input of Powerful Microwave Pulses at Ecr // Problems of Atomic Science and Technology. 2018, № 4, p. 91.

7. V.S. Antipov, A.N. Antonov, V.A. Buts, I.K. Kovalchuk, E.A. Kornilov, V.A. Vinokurov. Investigation of Posibility of Energy Transfer to Plasma Ions by Oscillations with Large Amplitude on Frequency of Electron Cyclotron Resonance in Magnetic TRAP. ISSN 1562-6016 // Problems of Atomic Science and Technology. Series "Plasma Physics”. 2018, № 6, p. 172-175.

8. K.F. Sergeichev, D.M. Karfidov, N.A. Lukina. ECR acceleration of electrons by a microwave field to relational energies in a mirror magnetic trap // Plasma Physics. 2007, v. 33, № 6, p. 505-525.

9. I.M. Podgorny. Lectures on plasma diagnostics. M.: "Atomizdat", 1968, p. 27.

10. S.P. Shary. Course of computational methods. Institute of Computational Technologies SB RAS Novosibirsk State University. Novosibirsk, 2019, p. 164.

11. J.M. Dowson, H.C. Kim, D. Arnush, et al. The ion energy in a plasma resonator excited by a powerful microwave pulse at ecr frequency // Phys. Rev. Lett. 1976, v. 37, p. 1547.

Article received 21.01.2020 


\section{ЭНЕРГИЯ ИОНОВ В ПЛАЗМЕННОМ РЕЗОНАТОРЕ, ВОЗБУЖДАЕМОМ МОЩНЫМ СВЧ-ИМПУЛЬСОМ НА ЧАСТОТЕ ЭЦР}

\section{А.Н. Антонов, В.С. Антипов, Е.А. Корнилов, В.А. Мирошниченко, В.А. Винокуров}

Экспериментально показана возможность нагрева ионов аргоновой плазмы плотностью $\approx 10^{13} \mathrm{~cm}^{-3}$ до 2 кэВ в резонаторе, размещенном в магнитном поле пробочной конфигурации, при возбуждении колебаний на частоте электронно-циклотронного резонанса и напряженности электрического поля до $12 \mathrm{\kappa B} / \mathrm{cm}$ в импульсе длительностью 1,8 мкс. Ионы приобретают высокую энергию в полях стохастических низкочастотных ионных колебаний, обусловленных развитием модифицированного распада СВЧ-колебаний.

\section{ЕНЕРГІЯ ІОНІВ У ПЛАЗМОВОМУ РЕЗОНАТОРІ, ЗБУДЖУВАНОМУ ПОТУЖНИМ НВЧ-ІМПУЛЬСОМ НА ЧАСТОТІ ЕЦР}

\section{О.М. Антонов, В.С. Антіпов, С.О. Корнілов, В.А. Мирочниченко, В.О. Винокуров}

Експериментально показана можливість нагріву іонів аргонової плазми щільністю $\approx 10^{13} \mathrm{~cm}^{-3}$ до 2 кеВ у резонаторі, розміщеному в магнітному полі пасткової конфігурації, при порушенні коливань на частоті електронно-циклотронного резонансу і напруженості електричного поля до $12 \mathrm{\kappa B} / \mathrm{cm}$ в імпульсі тривалістю 1,8 мкс. Іони набувають високу енергію в полях стохастичних низькочастотних іонних коливань, обумовлених розвитком модифікованого розпаду НВЧ-коливань. 